RECIIS - R. Eletr. de Com. Inf. Inov. Saúde. Rio de Janeiro, v5, n.4, p.14-23, Dez., 2011

[www.reciis.icict.fiocruz.br] e-ISSN 1981-6278

* Artigo Original

\title{
Saúde e estética: a medicalização da beleza ${ }^{1}$
}

\author{
Ana Lucia de Castro \\ Universidade Estadual Paulista Júlio de Mesquita Filho, Faculdade de Ciências e Letras de Araraquara, \\ São Paulo, Brasil \\ castroanalucia75@gmail.com
}

DOI: $10.3395 /$ reciis.v5i4.553pt

\begin{abstract}
Resumo
Este artigo discute os dados levantados em trabalho de campo realizado no Brasil e na Inglaterra, envolvendo a coleta de informações em material de imprensa, dados em arquivos, entrevistas e observação em clínicas estéticas (localizadas em São Paulo e Londres). O artigo toma como problemática central a discussão acerca da cirurgia plástica para fins estéticos como expressão da medicalização da sociedade e da difusão de princípios estruturadores da cultura de consumo. Como desdobramento, desenvolve-se em torno das perguntas: Que impactos a percepção de uma nova forma corporal gera na subjetividade? No caso das mulheres, a cirurgia plástica seria uma prática condicionada pelos ditames dos padrões histórica e culturalmente construídos, que associam a feminilidade a um padrão de beleza socialmente estabelecido, ou poderia ser entendida como uma fonte de poder do indivíduo? Seria, então, um exercício de agência?
\end{abstract}

Palavras-chave: cirurgia estética; culto ao corpo; medicalização; cultura de consumo; agência; empoderamento

\section{Introdução}

Este trabalho busca contribuir, em âmbito geral, para a compreensão da relação corpo e sociedade, tomando a cirurgia plástica para fins estéticos como expressão da medicalização dos comportamentos sociais, bem como da difusão de princípios estruturadores da cultura de consumo. Na esteira das reflexões de Mary Douglas (1976), que demonstra a evidência do simbolismo social no corpo humano, tomamos o corpo como expressão da sociedade e dos modos de vida cotidianos, ou seja, os hábitos sobre ele adotados e os padrões que definem sua normalidade e aceitação são a representação da organização social na qual está inserido.

Ao lado disso, partimos do pressuposto de que o corpo é locus comunicacional, tanto pela linguagem/gestualidade, como pela forma, que, como coloca Featherstone, é culturalmente codificada para operar como um indicador de poder social e prestígio (Castro, 2007; Featherstone, 1993:55). Neste sentido, vale lembrar Bourdieu (2007), que demonstra como a linguagem corporal é marcadora de distinção social, sendo o consumo alimentar, cultural e a forma de apresentação as três mais importantes maneiras de distinguir-se.

A crescente demanda por cirurgias estéticas configura-se num fenômeno heurístico para a análise da intersecção entre os discursos sobre saúde e beleza, propiciando a reflexão sobre dois aspectos da cultura contemporânea: a medicalização dos discursos e práticas sociais e a difusão de dois importantes princípios estruturadores da cultura de consumo: sedução e volatilidade. De um lado, trata-se de uma das mais radicais maneiras de intervenção médico-cirúrgica na forma corporal e de outro, configura como uma modalidade de consumo cultural que envolve, sobretudo, uma dimensão simbólica, impalpável; no discurso dos entrevistados, o que se afirma buscar, ao se submeter a este tipo de intervenção cirúrgica, é algo que nada tem de palpável ou concreto: beleza, prestígio, aceitação social, bem-estar, elevação da auto-estima.

Como recorte empírico para este estudo, desenvolvemos um trabalho de campo realizado em clínicas estéticas nas cidades de São Paulo e Londres, envolvendo levantamento de dados em arquivos e materiais de imprensa, registros em diários de campo e, no caso da primeira cidade, entrevistas com médicos e pacientes. Com base nos dados levantados, buscamos perceber as similaridades e diferenças nos sentidos construídos e atribuídos à prática da cirurgia estética nas duas realidades sócio-culturais, nas quais as disposições corporais são visivelmente díspares.

Assim como no Brasil, o número absoluto de cirurgias realizadas na Grã Bretanha só vem crescendo 
na última década. O maior salto (de 300\%) se deu entre 2003 e 2008, ano em que foram realizados 34.100 procedimentos cirúrgicos para fins estéticos, segundo a BAAPS (British Association Aesthetics Plastic Surgeon). Segundo Featherstone, em 2009 foram realizadas mais de 36 mil operações, configurando-se num crescimento de 6,7\% em relação a 2008. (Featherstone, 2010:215). Fazendo as contas, temos por volta de 60 procedimentos para cada 100 mil habitantes, enquanto no Brasil, segundo pesquisa Ibope, encomendada pela Associação Brasileira de Cirurgia Plástica, tivemos, em 2009, 443.145 cirurgias para fins estéticos realizadas, ou seja, 233 para cada 100 mil.

\section{Os sentidos da cirurgia plástica:utilidade $x$ futilidade}

Uma interessante pesquisa realizada com mulheres britânicas (Gimlin, 2007) nos fornece algumas pistas para uma análise de cunho comparativo acerca dos sentidos assumidos pela prática da cirurgia estética no Brasil e na Inglaterra. Neste trabalho, a autora aponta para a idéia de "necessidade" permeando os discursos das mulheres inglesas, ao serem questionadas sobre as motivações para a realização da cirurgia. Em muitos casos, referem a necessidade médica, enfatizando o sofrimento físico e / ou dor emocional associados ao corpo antes da cirurgia.

O sofrimento pode ser materializado em sangramento, como o de uma entrevistada que reduziu os seios e se queixou que antes da cirurgia sofria com os seios que sangravam em decorrência da friç̧ão entre o tecido e a pele. Em oposição, outra entrevistada aumentou os seios, relatando enorme sofrimento na adolescência, por não ter o mesmo desenvolvimento das outras meninas. Problemas nos relacionamentos pessoais também foram relatados pelas entrevistadas, como por exemplo, dificuldades em praticar esportes ou desconfortos na intimidade sexual e problemas na relação conjugal.

Outra motivação apontada diz respeito à impossibilidade de se realizar atividades cotidianas e comuns, como por exemplo realizar a lipoaspiração, por não se conseguir encontrar roupas e biquínis adequados ao seu manequim.

Em um dos casos foi relatada a impossibilidade de dar continuidade à patinação artística, que era praticada desde a infância, mas foi abandonada na adolescência, com o crescimento desproporcional dos seios, fazendo com que o sonho de se tornar profissional fosse esquecido. Outra entrevistada inglesa conta que antes da cirurgia saía para correr com fones de ouvido para não ouvir os comentários, principalmente dos homens, sobre suas grandes mamas balançando.

Os demais depoimentos de mulheres inglesas, analisados por Gimlin (2007) também foram nesta linha de apontar a cirurgia plástica como uma necessidade - em contraposição à noção de futilidade na medida em que se configura como forma de integração social, uma maneira de sair de um estado de exclusão de atividades cotidianas. O corpo pré cirurgia é sempre apontado como uma fonte de desvantagem, colocado como um obstáculo às atividades do dia a dia, supostamente disponíveis às "pessoas normais". Neste sentido, p odemos trabalhar com a hipótese de que assumir a vontade de fazer a cirurgia plástica pura e simplesmente para modelar o corpo e aproximá-lo de um ideal de beleza se choca com os princípios de valorização da noção de utilidade e desvalorização do fútil e efêmero, presentes na ética puritana, historicamente arraigada no modo de vida inglês.

Quanto aos apelos publicitários das clínicas estéticas inglesas, percebemos que algumas estratégias não diferem muito das utilizadas por aqui. O conhecido ANTES e DEPOIS é um recurso bastante recorrente, além da divulgação de testemunhos e depoimentos pessoais sobre as mudanças provocadas após a cirurgia.

Contudo, podemos perceber, como ilustrado pelas imagens abaixo - extraídas de panfletos publicitários do site da clínica investigada - que nos anúncios ingleses as fotografias não são retocadas ou submetidas a programas de computadores, como photoshop. As marcas da cirurgia permanecem, como que lembrando ao expectador da mensagem que se trata de uma intervenção médico-cirúrgica. 

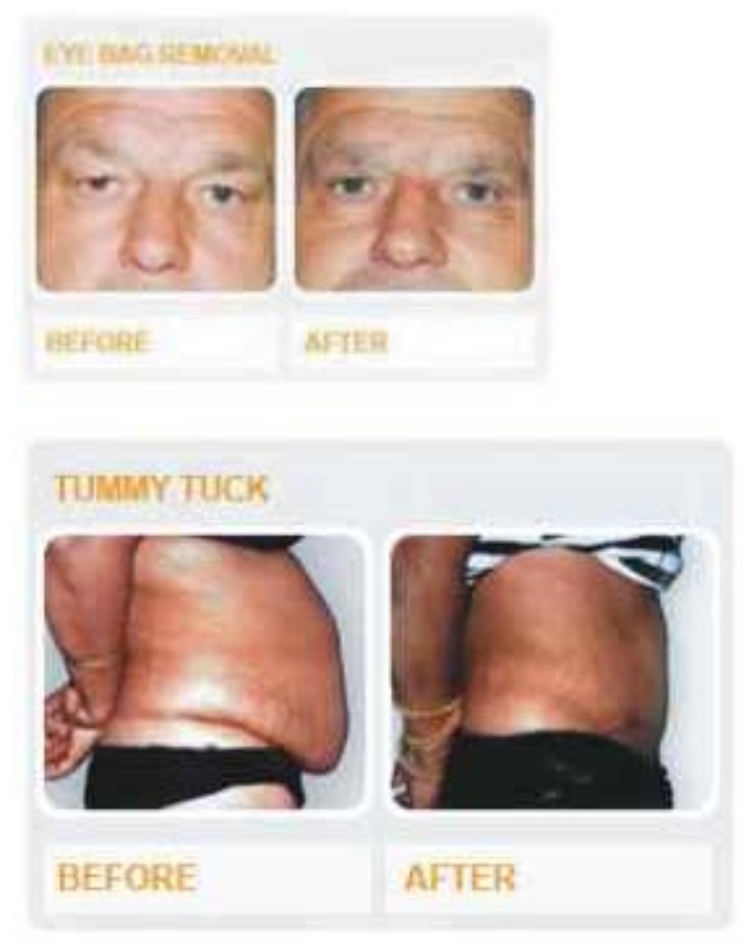

Em contraposição, nos anúncios brasileiros percebemos uma atenção maior para o tratamento da imagem, que se traduz no apagamento das marcas da cirurgia e numa tendência a se mostrar mais partes do corpo, além da que sofreu intervenção cirúrgica, como observamos nas figuras abaixo, retiradas dos sites de duas clínicas em São Paulo.

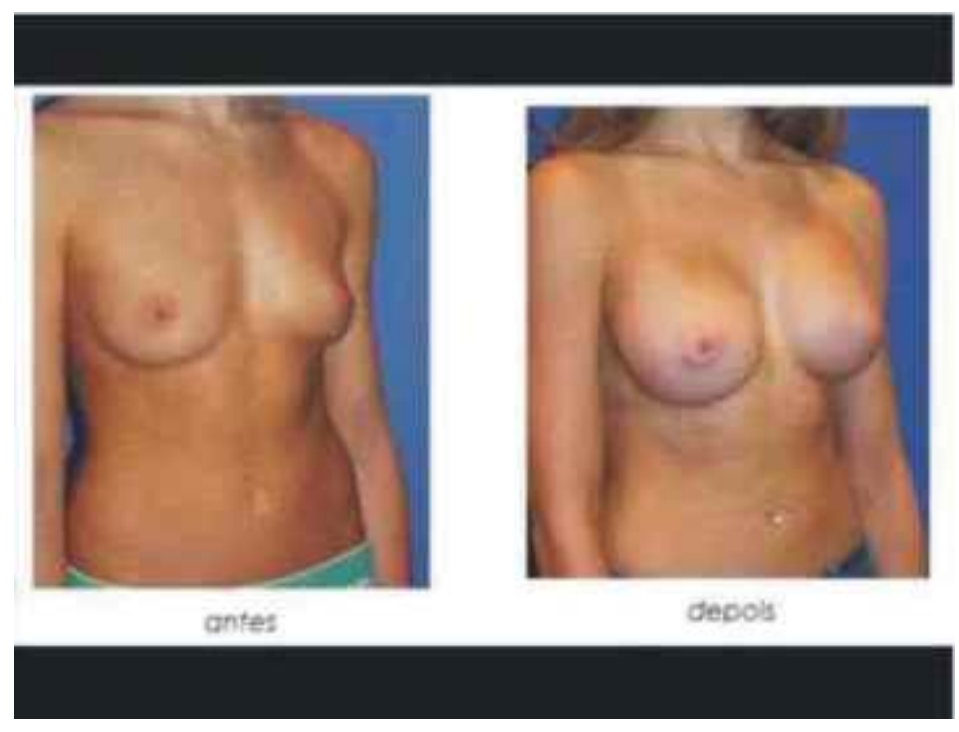




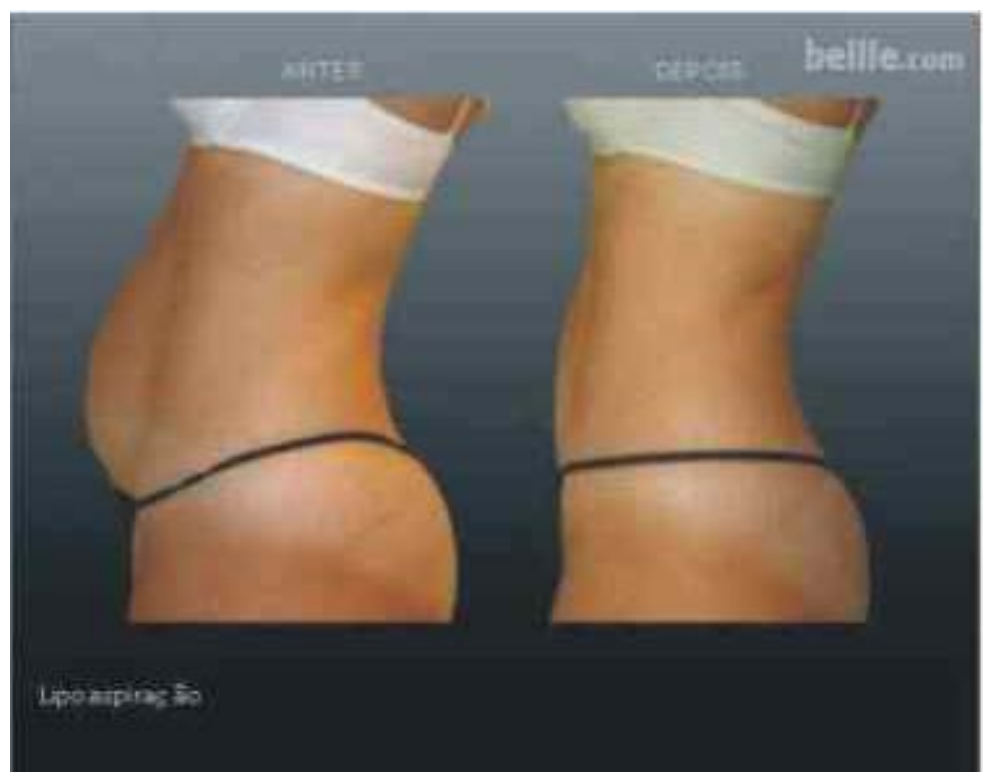

* Fotos de lipoaspiração

A chamada para o preço acessível, sugerindo que o custo não é uma barreira e a cirurgia é algo ao alcance de todos, também foi percebida na Inglaterra, embora em proporções menores do que no Brasil.Abaixo, observamos a fotografia de um cartaz, retirada num Shopping Center da cidade de Birminghan, indicando o preço como elemento de convencimento. Curioso notar que a modelo está totalmente vestida, deixando à mostra apenas parte dos seios.

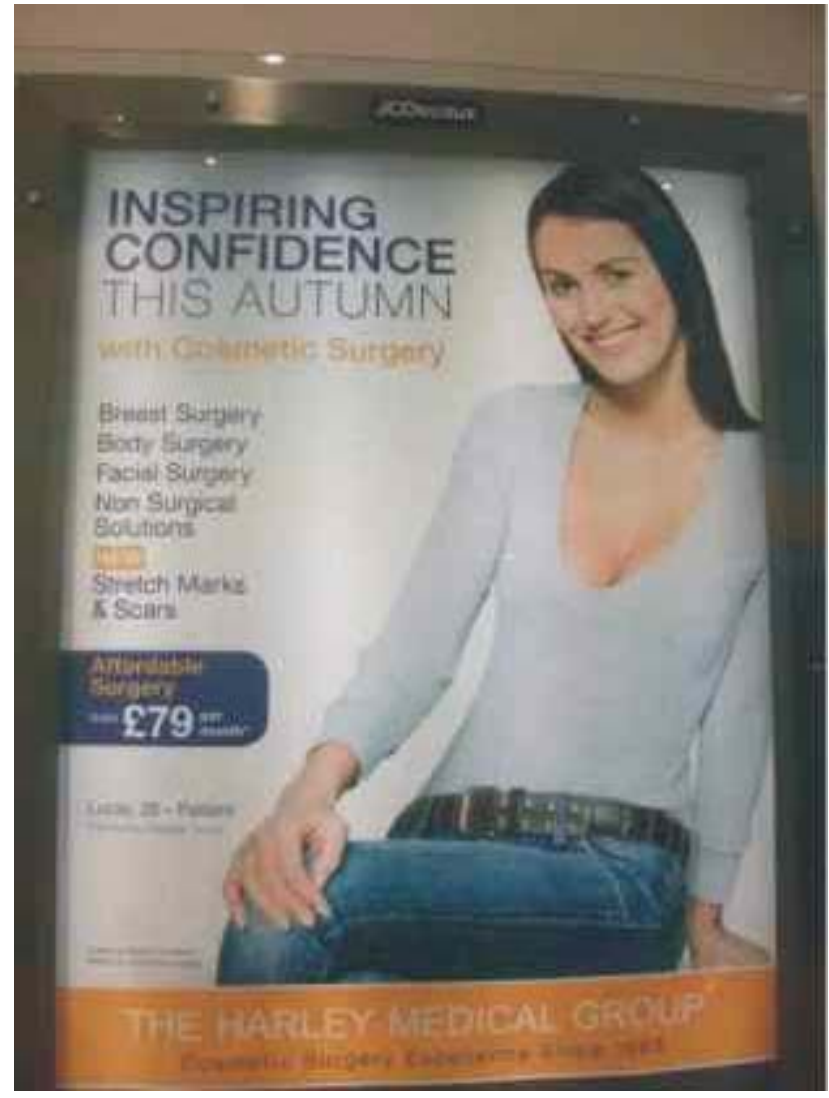

Bem diferentes são os anúncios das clínicas brasileira, que expõem o corpo na íntegra, em geral de forma insinuante e sedutora, como ilustrado pela figura abaixo: 


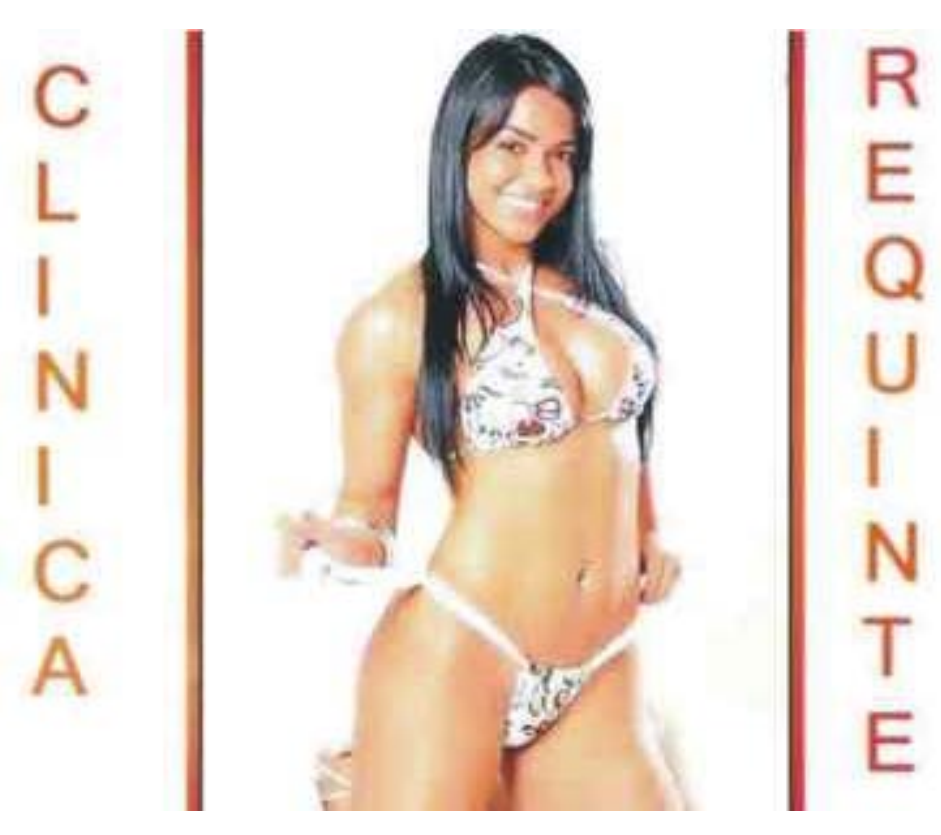

\section{Descrição}

Fórmulas para Emagrecimento.

Mini lipo escultura.

Drenagens linfáticas.

Botox.

Preenchedores faciais e labiais.

Peeling para rejuvenescimento facial.

Hormonio anti IDADE (GH).

Aumento de mamas sem cirurgia

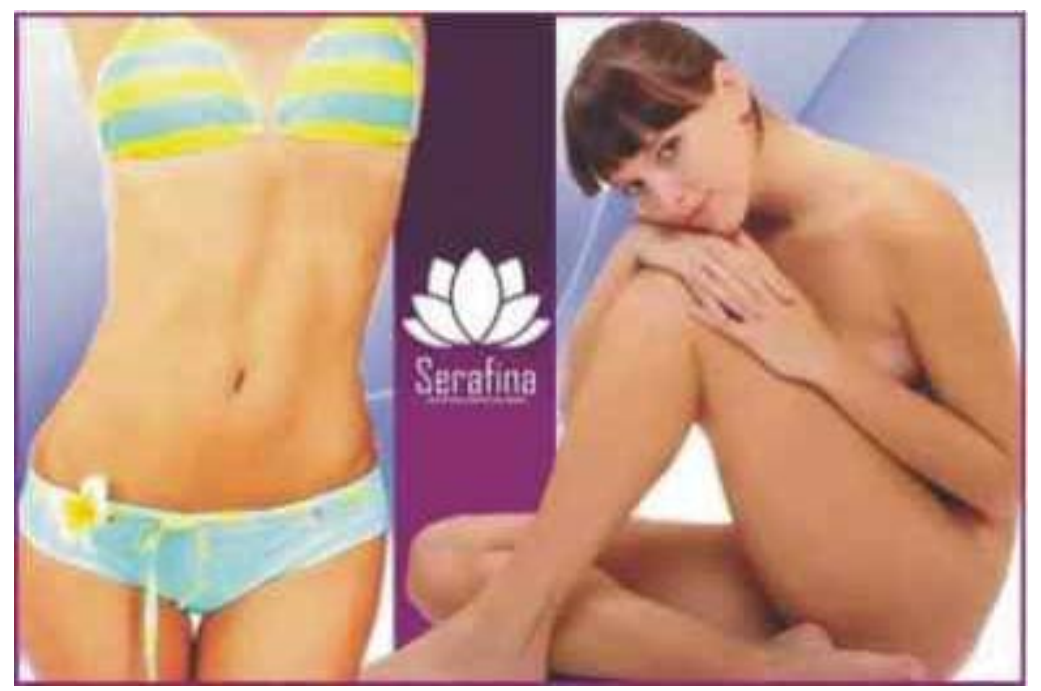

A linguagem publicitária mais direta no Brasil, que expõe o corpo e trabalha a imagem chamando atenção para a questão estética com apelos que, muitas vezes, resvala para uma linguagem erótica, encontra correspondência também nos discursos das mulheres entrevistadas. $O$ trabalho de campo realizado concentrou-se em uma clínica particular localizada no Bairro do Ibirapuera, zona nobre da cidade de São Paulo, e revelou, por parte das mulheres entrevistadas, a atribuição de sentidos diversos à presença da cirurgia plástica em suas vidas, mas sempre com uma centralidade muito grande da justificativa de fundo estético.

Nos depoimentos fornecidos pelas entrevistadas nesta clínica de São Paulo, a vaidade e a preocupação com a estética são apontadas sem tantos pruridos, quando comparamos aos discursos das inglesas, e as justificativas para a realização da cirurgia tanto são referidas a um outro (agradar ou segurar o marido/ amante), como passam por uma auto-afirmação e fortalecimento pessoal

Em alguns casos, esta busca de se transformar para manter um relacionamento chega a extremos, como o caso relatado, por exemplo, por Diana, 43 anos, que procurou a cirurgia plástica para melhorar a silhueta, pois o marido estava tendo um caso com a secretária. A médica respondeu: 
Mesmo com o melhor que posso fazer, vc não vai poder concorrer com a secretária de 22 anos. Diana foi embora e não mais voltou . $^{3}$

Quanto mais adentramos nos discursos em circulação e sentidos construídos em torno da prática da cirurgia estética nos dois países, mais evidente fica que no Brasil, ocorre uma maior banalização e menos cerceamento e constrangimentos morais, o que vem corroborar o apontado por Edmonds (1992) em seu estudo sobre a cirurgia plástica na cidade do Rio de Janeiro. Esta banalização chega a tal ponto que a cirurgia estética pode chegar a se configurar como uma espécie de vício. Vários relatos coletados na sala de espera da clínica apontaram nesta direção. Diante do resultado positivo, a paciente esquece o sofrimento pós-operatório e meses depois ou no ano seguinte retorna. Este é o caso de Janice, que chegou no consultório afirmando: não quero me cortar, estou prestes a ser avó e só quero ficar bem pro meu neto que vai chegar...quero melhorar só um pouquinho. ${ }^{4}$ Após a realização de peeling - tratamento à base de ácidos e cremes -, notou que a pele do pescoço , por ser uma região onde este tipo de tratamento não é recomendável, destoava muito da face. Então, resolveu entrar na faca e fazer uma cirurgia. Agora, está desejando fazer uma lipo.

Caso similar encontramos na experiência de Matilde, dona de casa que, após a entrada das duas filhas na idade adulta, passou a cuidar da parte de secretaria da oficina mecânica de propriedade do marido. O trecho de seu depoimento, abaixo destacado, demonstra a maneira como ela foi se "acostumando com a idéia" da cirurgia aos poucos e a colocando em sua vida como um bem de consumo ao qual recorre cada vez com mais freqüência.

"Há dez anos, quando vi minha irmã sofrendo na recuperação após a lipoescultura que fez, não me via fazendo aquilo de jeito nenhum.... achei aquilo um absurdo, um horror... ela toda roxa, costurada, com dor, tendo que andar curvada por um tempão.... pensei comigo: jamais. Mas aí o tempo foi passando, ela ficou bem, outras pessoas que conheço fizeram, a plástica barateou muito... então comecei a pensar em aarrumar meu nariz, que sempre me incomodou por ser muito grande e largo e há mais ou menos uns três anos fiz o nariz. Adorei o resultado, me fez tão bem, que comecei a pensar em fazer uma geral no corpo, tirar barriga, levantar e aumentar o peito, sabe... voltar a pôr roupas mais justas... e fui guardando um dinheirinho.... Agora fiz a lipoescultura, nossa, radical.... ainda tô sofrendo com a recuperação... tive arrependimentos.... semana passada mesmo acordei um dia chorando, mal conseguia me mexer na cama, com dores, passei o dia todo com vontade de voltar atrás e não ter feito.... mas fui melhorando, agora me sinto cada dia mais forte". 5

Esta entrevistada estava, no momento de coleta deste depoimento, com 20 dias de cirurgia e, ao ser perguntada se faria novamente uma cirurgia para fins estéticos, disse:

"Se eu faria outra.... espero conseguir controlar a boca e não mais precisar fazer na barriga, mas nos braços e pescoço penso sim.... só não aproveitei e fiz desta vez porque a médica disse que eu perderia muito sangue. " 6

Este último trecho do depoimento nos remete ao que ficou conhecido no meio estético como síndrome de Jáqui. Em algumas situações, na busca pela perfeição, o paciente se empolga com a possibilidade de "maximização da compra e esquece a situação de risco". Trata-se de uma espécie de categoria nativa, aparecendo como expressão utilizada por várias entrevistadas, que afirmam terem sido acometidas pela síndrome de Jáqui: Já que estou aqui... vamos aproveitar e tirar daqui, colocar ali... Este é o caso de Irene, que aos 45 anos, entrou no consultório decidida a fazer uma lipoaspiração e acabou fazendo lipoescultura, procedimento que afina cintura, retira gordura localizada do abdomen e injeta nas nádegas ou na região que se queira adensar/avolumar.

Ocorre que se não houver uma mudança de hábito alimentar, com o tempo o corpo volta a acumular gordura e a insatisfação retorna. Irene, novamente, aos 56 anos, está de volta ao consultório em busca de uma nova lipo.

Fátima, 43 anos, também está de volta ao consultório pela segunda vez. Na primeira, aumentou os seios e fez lipoaspiração. Agora, quer novamente se submeter a uma lipo. Ao ser perguntada sobre a experiência de realizar duas cirurgias, ela respondeu: não me importo com o pós-operatório, doer, dói... mas passa e o resultado é ótimo. O único problema é ficar olhando para o canhoto do cheque que meu marido deixa na porta da geladeira para me lembrar que tenho que manter a forma. 7

Esta banalização do risco, percebida dentre os freqüentadores da clínica em São Paulo, foi questionada junto aos profissionais de saúde. Quando indagada sobre os cuidados e preocupações em se passar aos pacientes as informações sobre o sofrimento e os riscos envolvidos ao se submeterem 
à cirurgia, uma médica entrevistada respondeu:

"Informo detalhadamente todos os riscos e as condições necessárias para recuperação, mas os pacientes têm ouvidos seletivos, não querem ouvir este lado da estória.... mas também sempre digo que eles correm mais risco para chegar em meu consultório do que na mesa de cirurgia". 8

Contudo, ao levantarmos a questão junto às mulheres operadas, as mesmas foam unânimes em afirmar que não tinham idéia que iriam viver tamanho sofrimento e que a Dra não havia enfatizado este aspecto nas consultas pré-operatórias. Os riscos são grandes, e podem ser fatais. Como forma de preveni-los, é necessário fazer uma boa anamnese e uma bateria de exames pré-operatórios, como por exemplo, ultrassom da parede intestinal para evitar perfuração, no caso de lipoaspiração.

Do ponto de vista do cirurgião, o mais terrível risco é, obviamente, a morte do paciente. Uma médica entrevistada relata: felizmente nunca perdi nenhum paciente em mesa, mas tive alguns de complicações sérias, que passaram por risco de vida em decorrência da cirurgia. ${ }^{9} \mathrm{O}$ primeiro caso foi o de uma ex-enfermeira que com ela havia trabalhado, em quem a médica entrevistada realizou uma lipoaspiração e depois de alguns dias foi internada queixando-se falta de ar. Estava com embulia pulmonar, como evolução de uma trombose, um tipo de seqüela que pode ocorrer neste tipo de cirurgia.

Outro caso curioso é de um paciente que a procurou para fazer uma lipoaspiração. Era paquito ${ }^{10} \mathrm{e}$ precisava ficar em forma para os shows e quase morre após a anestesia, na mesa de cirurgia, por uso de drogas na noite anterior à cirurgia. Nas palavras da entrevistada:

"Ele parou quando eu estava me escovando e me preparando para a cirurgia. A Anestesista me chamou, estava tudo parado... Saí e falei com o namorado, que depois de muito custo confessou que ele tinha saído na noite anterior e tomado droga. Depois de horas, ele acordou, passou a mão na barriga, descobriu que não tinha feito a cirurgia e ficou inconformado. Expliquei-lhe os motivos por não tê-lo operado e ele respondeu que preferia ter morrido lipado". 11

Um terceiro caso foi de uma secretária, que desenvolveu uma septicemia no pós-operatório e depois de muita investigação descobriu-se que era um simples absesso dentário que evoluiu, com a baixa de imunidade comum a qualquer cirurgia, a uma septicemia.

Em suma, o que percebemos é que no Brasil, assim como na Inglaterra, a cirurgia plástica configurase como uma espécie de solução mágica que vem solucionar os conflitos dos indivíduos com sua auto-imagem. Contudo, dentre nós há uma certa banalização do risco, bem como menos constrangimentos morais em torno da prática, dispensando, em certo sentido, a necessidade de uma "justificativa plausível" para a submissão à cirurgia. Dentre as britânicas, por outro lado, há um sentimento de "vergonha" envolvendo a realização da cirurgia estética, talvez pelo fato de que a ética puritana esteja mais presente na constituição do ethos inglês, que ainda impõe a idéia de necessidade - em contraposição à de luxo ou futilidade - para justificar este tipo de consumo.

\section{Cirurgia estética: questão de gênero?}

A cirurgia plástica para fins estéticos sempre foi mais procurada por mulheres. Das cirurgias realizadas na Inglaterra no último ano, $90 \%$ foram em mulheres e a principal procura foi pelo aumento dos seios (Featherstone, 2010), enquanto no Brasil, segundo dados da Associação Brasileira de Cirurgia Plástica, tivemos, em 2009, $80 \%$ de cirurgias realizadas em mulheres, das quais $29 \%$ foram lipoaspiração e $19 \%$ aumento dos seios por meio de implante de silicone. Tudo parece indicar que os homens guardam uma certa reserva, envergonhando-se quando assumem a preocupação com a aparência, ainda identificada como "coisa de mulher". A pesquisa desenvolvida por Antonio (2008), com pacientes que se submeteram à cirurgia no Hospital das Clínicas de Campinas indica que as mulheres pó ela entrevistadas, quando comparadas aos homens, demonstram menos resistência em assumir a preocupação estética como justificativa ou motivação para a realização da cirurgia. Conforme a autora:

"As justificativas tanto dos homens quanto das mulheres para as cirurgias também foram centradas nos aspectos psicológicos como "traumas", "vergonha", "baixa autoestima"; porém, nos discursos das mulheres apareceram outras categorias como "razão ou motivos estéticos", "vaidade"que foram associados com 'bem-estar' pessoal. Algumas mulheres apontaram suas cirurgias como o"grande sonho" de suas vidas, outras chegaram a comparar-se com modelos de revistas de moda. Já, no discurso dos 
homens, não apareceram estas categorias mais claramente ligadas à beleza, e sim, os incômodos pessoais, psicológicos, dores nas mamas nos casos de ginecomastia, serem alvos de "zombaria" quando possuem mamas ou orelhas grandes. Entretanto, os discursos dos homens tenderam a ser mais reservados e, daqueles que entrevistei, dificilmente associaram suas cirurgias com os motivos de estética, não da maneira direta como encontrei em alguns discursos femininos". ( Antonio, 2008:33)

A construção cultural e histórica de um discurso medicalizante acerca das diferenças de gênero vem, ao longo da história, fundamentando uma articulação entre corpo feminino, práticas cosméticas e prática médica.

A regulação e o controle dos corpos femininos pela medicina foi bastante discutida por pesquisadores brasileiros, que sempre antenados a uma perspectiva de estudos de gênero (Butler, 2003; Chambers, 2007)), apontam as bases histórico-culturais sobre as quais se assentam o discurso das diferenças de gênero e o fenômeno da medicalização do feminino (Del Priore, 2001; Rohden, 2001; Citeli, 2001). Contemporaneamente, como aponta Ribeiro (2003), esta medicalização tem sua expressão mais bem acabada na prática da cirurgia plástica para fins estéticos, na medida em que promove o enquadramento do corpo nos padrões de beleza vigentes. A autora detecta, ainda, uma mudança nas formas de legitimação desta prática, cada vez mais assentada em um discurso psicologizante:

\begin{abstract}
..." o que parece é que a medicalização do corpo feminino que ocorre através das cirurgias plásticas, estéticas e corretivas, já não se legitima mais pelo mesmo discurso médico biologizante que, em séculos passados, continuamente determinou o que a mulher deveria fazer com seu frágil e fragilizado corpo... hoje passou-se do dicurso sobre um corpo "doente", construído sobre o "mito da mãe-útero"para o discurso psi (Ribeiro, 2003:7)".
\end{abstract}

A discussão acerca do controle e regulação dos corpos pelas ciências médicas não pode prescindir da contribuição de Michel Foucault $(1979,1985)$, recorrentemente lembradas por evidenciar a função de controle social que a biomedicina vem desempenhando historicamente. Com a noção de biopoder, Foucault demonstra como as ciências biológicas, especialmente a medicina, vêm atuando na promoção da docilização e disciplinamento do corpo, assumindo o papel anteriormente desempenhado pelo discurso moral.

Embora partindo de outros pressupostos teóricos, Lipovestsky (2007) aponta para um fenômeno análogo, ao discutir a medicalização do consumo como traço das sociedades contemporâneas, por ele denominada de sociedade de hiperconsumo. Na argumentação do autor, o crescente aumento da demanda por produtos e serviços de saúde viria indicar a mudança nos sentidos do consumo, contemporaneamente mais ligados a uma busca individual de prazer e de experiências sensoriais, do que à de prestígio e estratégia de distinção social. Em suas palavras:

"Nada concretiza melhor o declínio do ethos do consumo pelo prestígio que a evolução das demandas e dos comportamentos relacionados à saúde... a competência médica estende-se a todos os domínios da vida para melhorar-Ihes a qualidade... Enquanto um número crescente de atividades e de esferas da existência toma uma coloração sanitária, os bens de consumo integram cada vez mais a dimensão da saúde: alimentos, turismo, hábitat, cosméticos, a temática da saúde tornou-se um argumento decisivo de venda." ( pp.53-53)

Paralelamente, uma outra vertente analítica vem indicando que a cirurgia plástica pode ser entendida como parte de um projeto corporal (Giddens, 1997; Antonio, 2008; Le Breton, 2008), bem como para o fato, também atestado por nossa pesquisa, de que a experiência da cirurgia provoca um grande impacto na subjetividade e na auto-imagem. Muitas mulheres descobrem ou redescobrem a sexualidade. Há casos de pacientes que aqueceram a relação sexual com o parceiro, enquanto outras passaram a manter um caso extra-conjugal. Minha alma tá mudando depois da cirurgia, passei ter alma de puta, afirma uma entrevistada. Este impacto na subjetividade, ligado à mudança na aparência corporal, provoca o debate relativo às noções de poder e agência. A decisão de realizar a cirurgia plástica seria um ato de poder, como proporia Csordas (1996), ou uma forma de tornar o corpo um objeto, que pacificamente se submete aos ditames dos padrões de beleza divulgados pela mídia e pela indústria do culto ao corpo?

Em suma, seja sob a justificativa puritana-utilitarista da necessidade ou narcísico-hedonista da busca pela beleza, a cirurgia plástica vem crescendo como prática recorrente, revestindo-se de um caráter naturalizante. Ela ganha força como forma de se conferir sentido à vida e de re-definição de subjetividades, num mundo em que, ao lado da proliferação da medicalização de comportamentos, cada vez mais, se evidencia a valorização da estética em detrimento da ética. Esta valorização é 
atestada pela percepção de que a busca do sentido da existência passa pela forma como se expõem as aparências - reveladora de uma "auto-observância" vigilante - e pelo imperativo da mudança constante, como receita de felicidade. Certamente não por acaso, estes são dois importantes princípios estruturadores da cultura de consumo: sedução e volatilidade.

\section{Referências bibliográficas}

ANTONIO, Andrea Tochio De. Corpo e estética: um estudo antropológico da cirurgia plástica. Dissertação de mestrado apresentada ao Programa de Pós-graduação em antropologia social, IFCH/Unicamp, 2008.

BOURDIEU, Pierre A distinção: crítica social do julgamento. São Paulo: EDUSP, Porto Alegre: Zouk, 2007.

BUTLER, Judith Problemas de gênero: feminismo e subversão da identidade. Rio de Janeiro, Civilização Brasileira, 2003.

CASTRO, Ana Lúcia Culto ao corpo e sociedade: mídia, cultura de consumo e estilos de vida. São Paulo, AnnaBlume/FAPESP, $2^{\text {a }}$ edição , 2007.

CHAMBERS, Samuel A' Sex' and the Problem of the Body: Reconstructing Judith Butler 's Theory. Body \& Society , Los Angeles/Londres/Nova Delhi e Singapura, 13(4): 47-75, 2007.

CITELI, Maria Teresa " Fazendo diferenças: teorias sobre gênero, corpo e comportamento". Revista Estudos Feministas,9(1):131-145, 2001.

CSORDAS, Thomas. J. Embodiment and Experience: The existencial ground of culture and self. New York: Cambrigde, University Press, 1996.

DOUGLAS, Mary. Pureza e perigo. São Paulo, Perspectiva, 1976.

EDMONDS, Alexander. "No universo da beleza: notas de campo sobre cirurgia plástica no Rio de Janeiro". In: GOLDENBERG, Mirian (org.) Nu e vestido: dez antropólogos revelam a cultura do corpo carioca. Rio de Janeiro, Record, 2002.

FEATHERSTONE, Mike. "O curso da vida: corpo, cultura e imagens do processo de envelhecimento". In: DEBERT, G. G. Antropologia e velhice, Textos Didáticos IFCH/UNICAMP, 1993.

FEATHERSTONE, Mike . "Body, Image and Affect in Consumer Culture". Body \& Society . (1)16: 193-221, mar/2010

FOUCAULT, Michel. Microfísica do poder. Rio de Janeiro, Graal, 1979.

GIDDENS, Anthony. Modernidade e identidade pessoal , Oeiras/Portugal, Celta Editora, 1997.

GIMLIN, Debra. Accounting for Cosmetic Surgery in the USA and Great Britain: A Cross-cultural Analysis of Women's Narratives. Body \& Society . Los Angeles/Londres/Nova Delhi/ Singapura, Sage Publication, 13(1):43-62, 2007.

LIPOVETSKY, Gilles. A felicidade paradoxal: ensaio sobre a sociedade de hiperconsumo. São Paulo, Cia das Letras, 2007.

RIBEIRO, L. B. Cirurgia Plástica estética em corpos femininos: a medicalização da diferença . Disponível em < http://www.antropologia.com.br/arti/colab/vram2003/a13-lbribeiro.pdf > Acesso em out. 2011.

ROHDEN, Fabíola. Uma ciência da diferença: sexo e gênero na medicina da mulher. RJ: Ed.FIOCRUZ, 2001.

\section{Notas}

1 Agradeço à FAPESP, que concedeu a Bolsa Pesquisa Exterior para a realização da pesquisa de campo na Inglaterra.

2 Vale lembrar que no Brasil é proibido, pelo Código de Ética Médica, a divulgação de preços de cirurgias em anúncios publicitários.

3 Registro em diário de campo, março/2010.

4 Depoimento de Janice, 57 anos, concedido para esta pesquisa em 12/04/10. Os nomes dos entrevistados citados 
neste artigo são fictícios.

5 Depoimento de Clotilde, 51 anos, concedido a esta pesquisa em 10/02/ 2011.

6 Idem.

7 Depoimento de Fátima, 43 anos, concedida a esta pesquisa em 26/04/2010.

8 Depoimento de Dra LCG, concedido a esta pesquisa em 28/01/10

9 Idem.

10 Paquitos e paquitas são os dançarinos e auxiliares da apresentadora de programa de televisão Xuxa.

11 Depoimento da Dra. L.C.G, concedido a esta pesquisa, em 28/01/10 